\title{
HIGH- EFFICIENCY CLASS E POWER AMPLIFIER USING SI-GE HBT TECHNOLOGY
}

\author{
J.A. Tirado-Méndez \& H. Jardón-Aguilar
}

Centre of Research and Advanced Studies - National Polytechnic Institute;Telecommunications Section Av. IPN, No. 2508, Col Sn. Pedro Zacatenco, México D.F., México

Received: January $29^{\text {th }} 2002$ and accepted October $3^{\text {rd }} 2002$

\begin{abstract}
One of the most important goals of RF circuit designers is improving efficiency and autonomy in handsets for personal communications. Currently, low-level voltage supplies are used to avoid big weight and volume. Besides, autonomy and efficiency are closely linked to the energy consumed by the circuits. Power Amplifier $(P A)$ is one of the circuits, which spends more energy from the battery. Improving the $P A$ efficiency, handset performance is also improved. Previous publications have mentioned the difference of power amplifiers where the circuit output works as I) a current source or II) as a switch. The class E power amplifiers are devices whose output works as a switch achieving great performance and high power efficiency, reaching, in an ideal case, $100 \%$ of efficiency. In this paper, a low-level voltage class E power amplifier is analyzed, designed, simulated, built and characterized, using a silicio-Germains HBT transistor as an active element. The circuit was optimized using a harmonic balanced simulator (Microwave Office ${ }^{\circledR}[1]$ ). 70\% power efficiency was measured after an optimizing procedure, although better performance can be expected with an improved switching transistor and more precisely lumped elements. The prototype was designed to operate at $900 \mathrm{MHz}$ and fed with $2.4 \mathrm{~V}$, but it is well known that low-level polarization voltages affect efficiency, linearity, power gain, bandwidth, noise figure, as well as cost in RF circuits. However the class E PA reported in this paper reaches high efficiency, high power gain as well as a good bandwidth, with lowlevel polarization voltage.
\end{abstract}

\section{RESUMEN}

Una de las principales metas de los diseñadores de circuitos de RF es llevar a cabo equipos personales de comunicación de mayor eficiencia y autonomía. Actualmente se utilizan fuentes de alimentación de bajos niveles con el fin de evitar peso y volumen excesivo en los sistemas personales. Además, la autonomía y la eficiencia están íntimamente ligadas a la energía usada por los circuitos. El amplificador de potencia es uno de los dispositivos que extrae más energía de la batería, por lo cual, incrementando la eficiencia del amplificador, se mejora el desempeño del equipo personal. En publicaciones anteriores se ha señalado la diferencia de los amplificadores de potencia donde la etapa de salida de éste trabaja como I) fuente de corriente o como II) interruptor. Un amplificador de potencia clase E es un circuito cuya salida trabaja como un interruptor, obteniendo un gran desempeño y poseyendo una gran eficiencia en potencia, alcanzando, en un caso ideal, el 100\%. En este artículo se analiza, diseña, simula, construye, y se caracteriza un amplificador de potencia clase E, usando un transistor HBT de Silicio-Germanio como elemento activo. El circuito se optimizó mediante un simulador de balance armónico (Microwave Office ${ }^{\circledR}[1]$ ). Se obtuvo una eficiencia medida del 70\%, después de un proceso de optimización, sin embargo, se puede esperar un mejor desempeño si se utiliza un transistor con mejores características y elementos discretos de mayor precisión. El circuito fue diseñado a una frecuencia de operación de $900 \mathrm{MHz}$ y polarizado con 2.4 V. Sin embargo, es bien sabido que bajos voltajes de polarización conllevan a una degradación de la eficiencia, la linealidad, la ganancia en potencia, el ancho de banda, la figura de ruido, así como el costo. El amplificador de 
High-Efficiency class E power amplifier using Si-Ge HBT technology, J.A. Tirado-Méndez \& H. Jardón-Aguilar, 95-106

potencia clase E reportado en este artículo posee una alta eficiencia, ganancia en potencia, así como un amplio ancho de banda con bajo nivel de polarización de voltaje.

KEYWORDS: High-Efficiency, Class E Power Amplifier, Low-level voltage.

\section{INTRODUCTION}

Class E power amplifier is a very non-linear circuit, but it can reach high power efficiency, near 100\% for an ideal operation.

The single-transistor class E power amplifier is shown in figure 1a. It consists of a RF choke (RFC), and an output network, conformed by a series RLC circuit and a shunt capacitor.
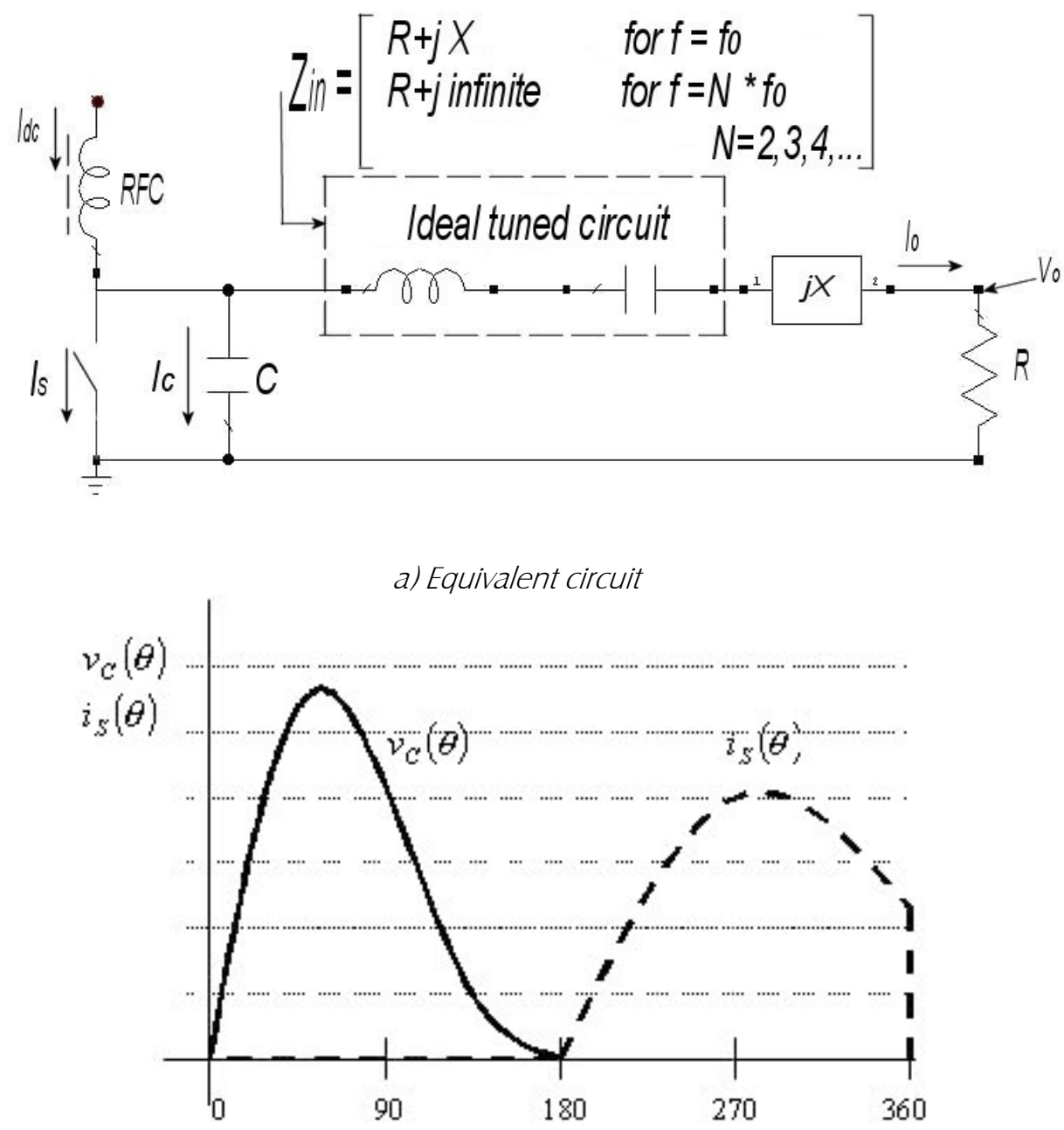

Angle $\theta$ [degrees]

b) Switch waveforms

Figure 1. Class E power amplifier 
The transistor operates as an ideal switch, and it gets a good performance if [2]:

1 The transistor keeps a low voltage level when it is on.

2 The transistor drives a low current when it is off.

3 The transition times are small enough compared with the signal period.

From points 1 and 3, it can be inferred that the resistance of the transistor has to be very small and the input signal has to be a square waveform with $50 \%$ duty cycle.

A good performance in class E power amplifier can be achieved by assuming four important points [3]: a) the RF choke has a large reactance so that the current from the source through it is constant, b) The $Q$ of the tuned circuit is big enough so that the output waveform is sinusoidal, c) The transistor works as an ideal switch, and d) The capacitance $\mathrm{C}$ is independent of the voltage.

\section{DESIGN METHODOLOGY}

No knowledge of transistor characteristics are necessary to design a class E power amplifier when it operates at low frequencies (less than $4 \mathrm{MHz}$ ) [4]. But when the circuit is designed to operate at RF or microwave frequencies, the intrinsic and parasitic characteristics of the transistor play an important role in the circuit's performance, resulting in degradation of efficiency and other parameters. To avoid the degradation due to these parasitics, an HBT transistor was chosen, because of its features at high frequencies. Although this kind of transistors also has intrinsic junction capacitances, the values are small enough to avoid a big degradation at $900 \mathrm{MHz}$ [5].

The circuit shown in figure 1a was analyzed in detail by Sokal [6] and Raab [7] who derived analytical expressions for an ideal circuit.

Figure $1 \mathrm{~b}$ shows the waveforms for the case of a $50 \%$ switching duty cycle of a class $E$ PA. The collector voltage is expressed by [3]:

$$
v_{C}(\theta)=\frac{I_{d c}}{B}\left(y-\frac{\pi}{2}\right)+\frac{V_{o m}}{B R} \sin (\theta-y)+\frac{I_{d c}}{B} \theta+\frac{V_{o m}}{B R}(\theta+\phi),
$$

where $y$ is the switch off-time in radians,

$B$ is the susceptibility of $C$ at the operation frequency,

$V_{\text {om }}$ is the optimum peak voltage at the output,

$\varphi$ is the signal phase and,

$\theta$ is the conduction angle.

To determine the values of $B$ and $X$ for optimum operation, it is necessary to obtain the derivative of (1) with respect to $\theta$, and set it equal to zero. This yields the next equations:

$$
\begin{gathered}
R=\frac{8 V_{C C}^{2}}{P_{\text {out }}\left(\pi^{2}+4\right)} \\
X_{L}=\frac{\pi V_{C C}^{2}\left(\pi^{2}-4\right)}{2 P_{\text {out }}\left(\pi^{2}-4\right)}
\end{gathered}
$$




$$
\begin{gathered}
L_{o}=\frac{8 Q V_{C C}^{2}}{\omega P_{\text {out }}\left(\pi^{2}+4\right)} \\
C_{o}=\frac{P_{\text {out }}\left(\pi^{2}+4\right)}{8 \omega V_{C C}^{2} Q} \\
C=\frac{P_{\text {out }}}{\pi \omega V_{C C}^{2}}
\end{gathered}
$$

where $R$ is the load, and $X_{L}$ is the excess inductance. Now, for $R=50 \Omega$ and a quality factor, $Q=5$, the resulting circuit is shown in figure 2 .

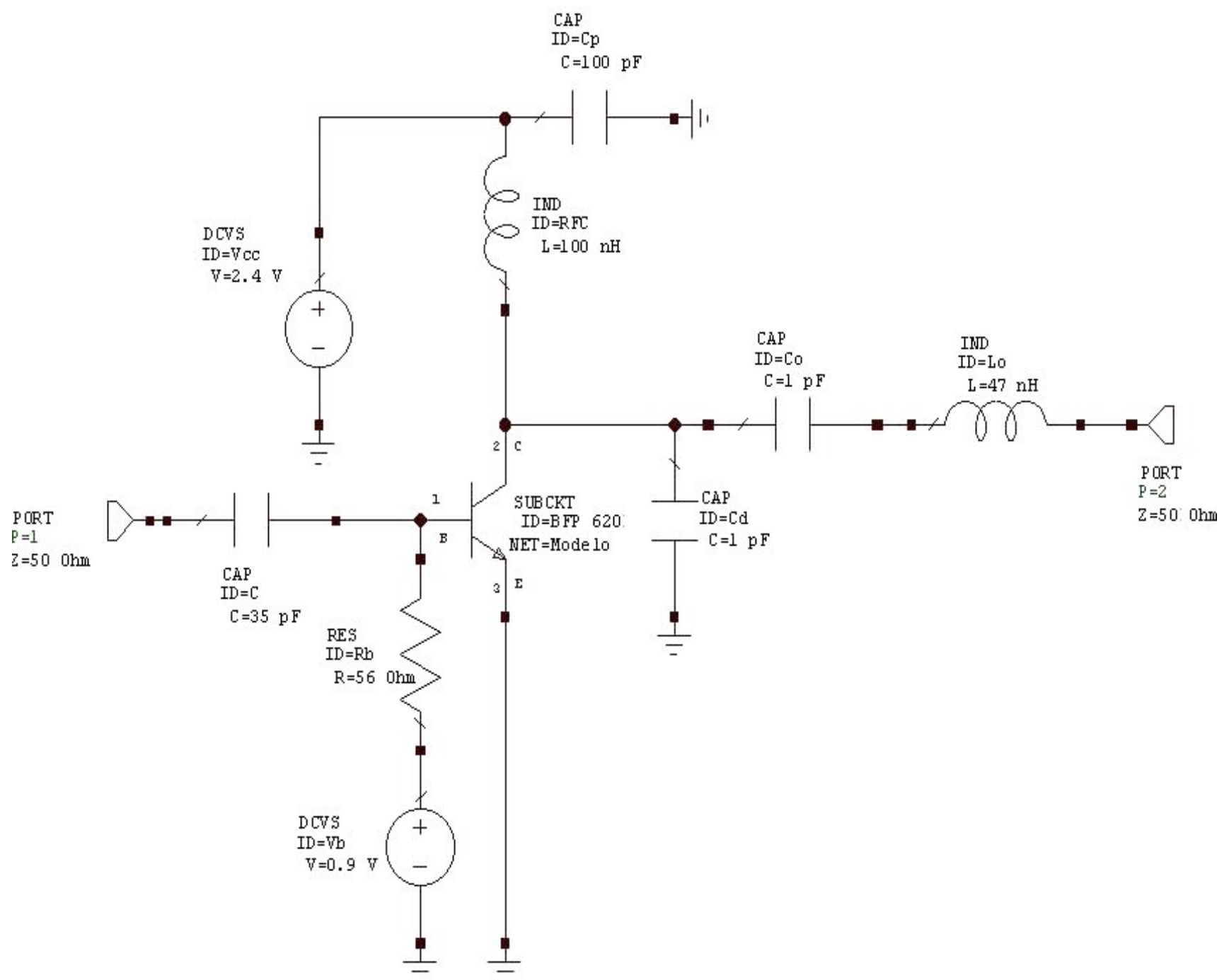

Figure 2. Optimized class E power amplifier 


\section{RESULTS FROM SIMULATIONS}

The optimization procedure was achieved by using the optimizer of two different software, Microwave Office and Advanced Design System from Agilent Tech. [8]. This procedure was realized taking into account the values of commercial lumped elements to get the best approach to real components and to obtain the maximum power efficiency and power gain at $900 \mathrm{MHz}$.

The simulated waveforms of the class E power amplifier are shown in figure 3, after having been optimized. The input power is set to $0 \mathrm{dBm}$.

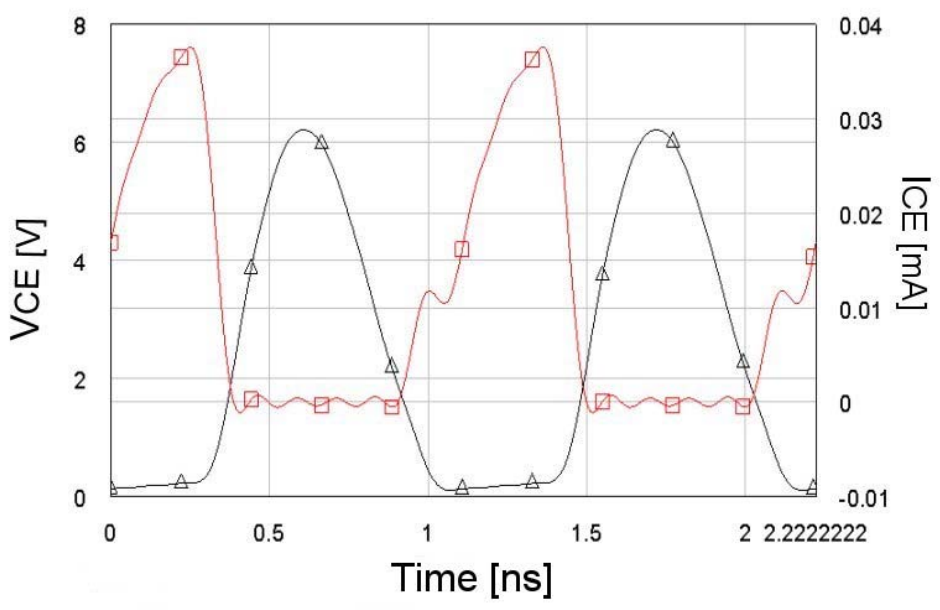

Figure 3. Class E PA simulated waveforms

Figure 4 shows the Power efficiency of the class E PA. In this figure a 83\% efficiency was gotten for a $27^{\circ}$ temperature, but when the temperature increases, the efficiency decreases. As can be seen in this figure, efficiency increases when the temperature is less than $27^{\circ}$. This phenomenon is explained by the Joule effect, where an increase in temperature causes the current to rise, and this increment in the current generates a temperature increase accordingly. This phenomenon can cause the destruction of the device [5].

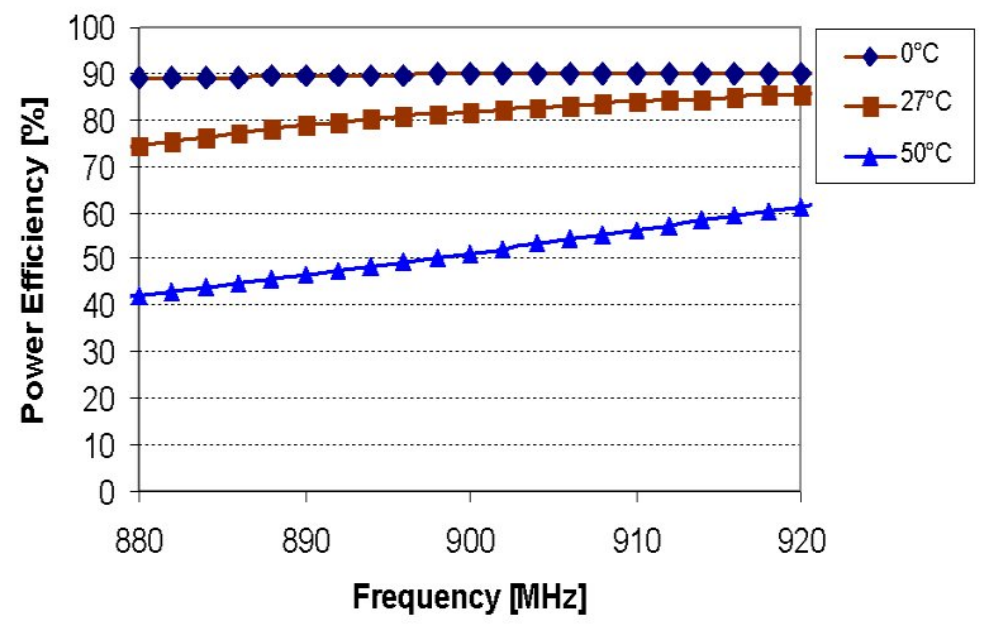

Figure 4. Simulated power efficiency for different operation temperatures 
In most cases, power gain is reduced when efficiency is increased, specially for those structures where the active device works as a current source. But in this case of the class $E$ PA, high efficiency could be reached without affecting the power gain and therefore the power delivered to the load. The gain of the $P A$ is shown in figure 5 , where the peak value is almost $12 \mathrm{~dB}$, at the operating frequency. This parameter is also affected by the temperature, showing a better performance when it is lower than the ambient temperature.

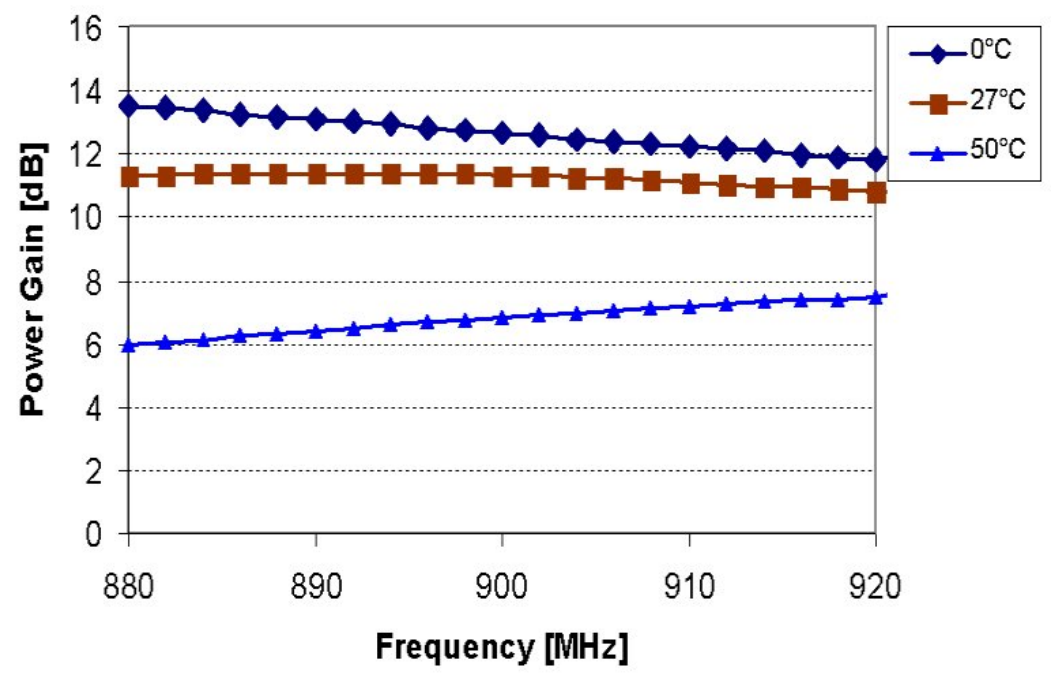

Figure 5. Simulated power gain for different operation temperatures

At this moment, class E PA has shown a considerable high-efficiency and a good power gain, but one of its great disadvantages is that this circuit is highly non-linear. Figure 6 shows the magnitude of the third-order intermodulation product (IM3). The IM3 reaches a magnitude higher at $0 \mathrm{dBm}$ when compared to the input power used for optimal operation in the simulation process $(0 \mathrm{dBm})$.

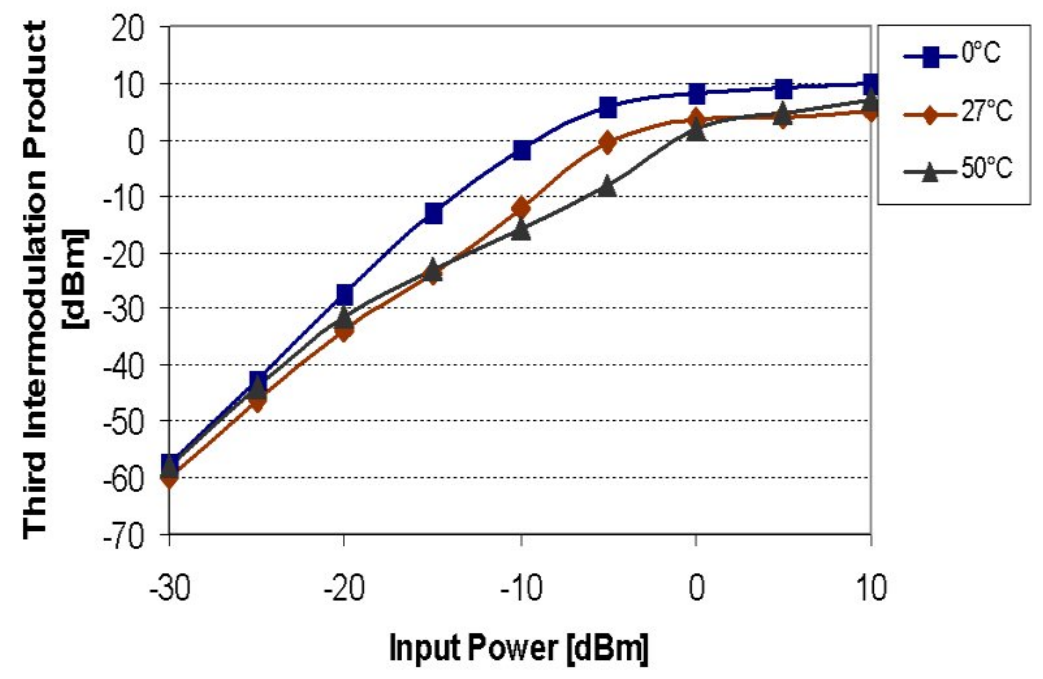

Figure 6. Simulated magnitude of third intermodulation product (IM3) for different operation temperatures 
Figure 7 shows the behavior of the power efficiency when the input power varies from $-10 \mathrm{dBm}$ to $15 \mathrm{dBm}$. It can be seen that the efficiency rises exponentially in a short power input range, reaching $83 \%$ at its optimal operation range $0 \mathrm{dBm}$. However, it should be noted that the efficiency is improved at lower temperature. In figure $7,83 \%$ efficiency is reached when the input power is $0 \mathrm{dBm}$ at $27^{\circ} \mathrm{C}$. But this efficiency can be achieved at lower power input signals if the operation temperature is lower than $27^{\circ} \mathrm{C}$, as can be seen for a $0^{\circ} \mathrm{C}$ case, where the input power signal is $-5 \mathrm{dBm}$ and the efficiency is also $83 \%$. This analysis is very important in practical applications, because the adequate input signal level must be found to allow the class E PA to work efficiently, that is, where the circuit switches ideally. A similar result was found in [9].

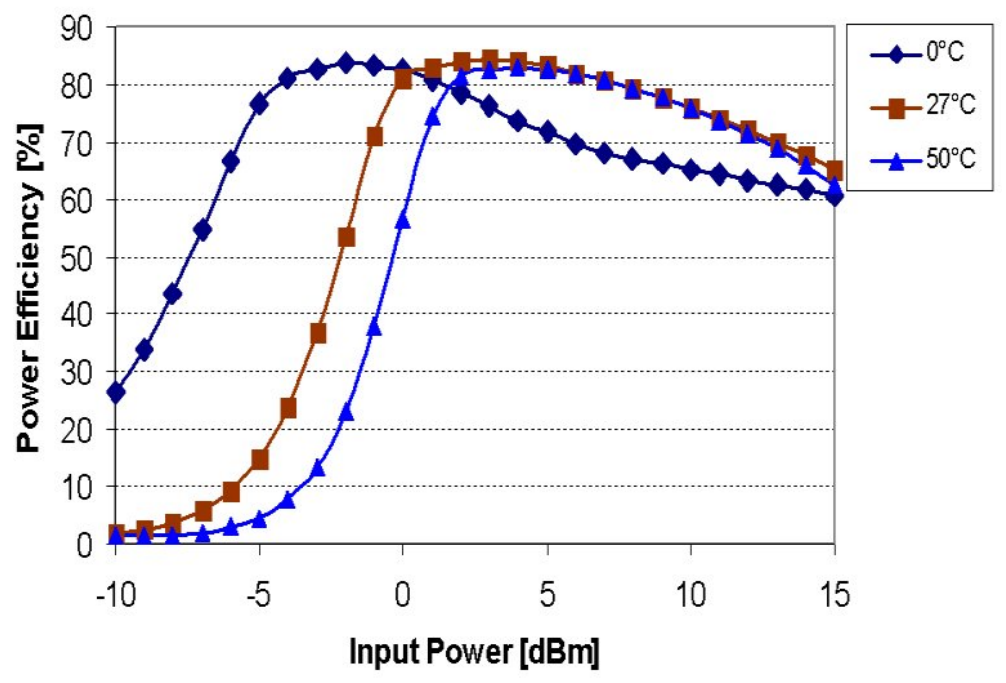

Figure 7. Simulated power efficiency against input power for different operation temperatures

\section{EXPERIMENTAL RESULTS}

In order to compare the simulation results, a class E PA operating at $900 \mathrm{MHz}$ was constructed. The first step is the design of the circuit layout. $50 \Omega$ transmission lines were designed to achieve matching between input and output. Figure 8 shows the layout of the circuit. SOT-343 packing was used for the BFP 620 HBT and 0805 packing was used for inductors, capacitors and resistors.

The material used for building the circuit is RT/duroid 6006 [10] with a permitivity of 6.15. SMA connectors were modified to avoid any mismatching between the microstrips and source and load. True holes were used to achieve a good ground connection improving low impedance at RF frequencies.

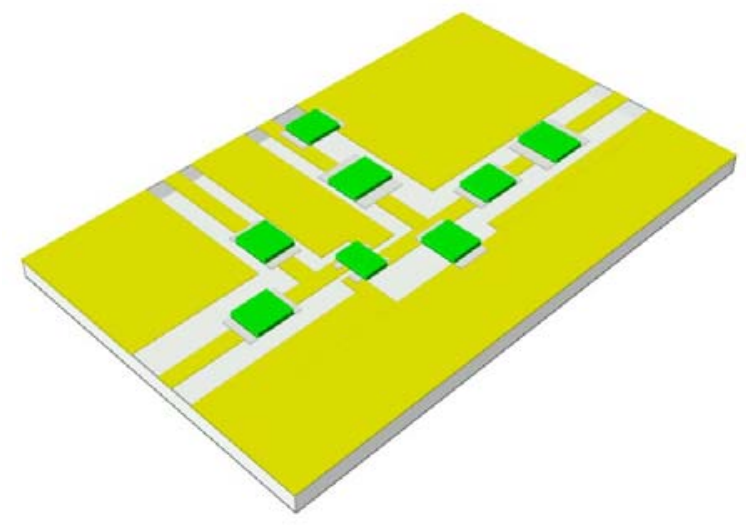

Figure 8. Class E PA layout 
The output signal spectrum was measured for a $900 \mathrm{MHz}$ and $0 \mathrm{dBm}$ input signal, the results are shown in figure 9. In this figure, it can be seen that the second and third harmonics are $-32 \mathrm{dBc}$ and $-45 \mathrm{dBc}$, respectively. Figure 10 shows the behavior of the fundamental component against input power, and it can be observed that, even in low input signal, the gain remains bigger than $9 \mathrm{dBm}$ until the circuit reaches its optimal input signal, where the obtained gain is more than $11 \mathrm{dBm}$.

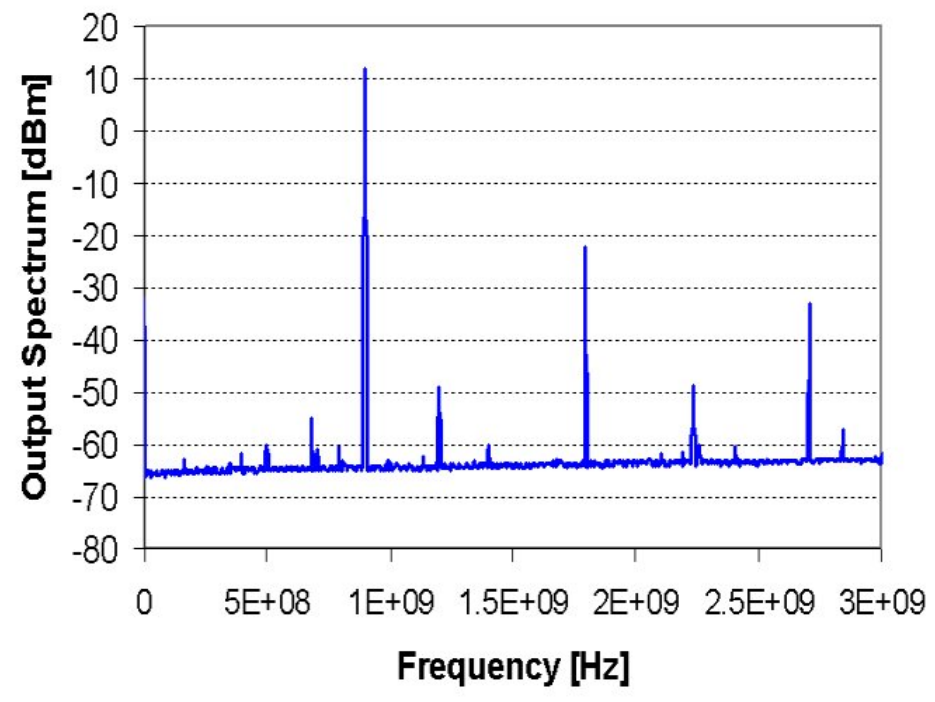

Figure 9. Class E PA output signal spectrum

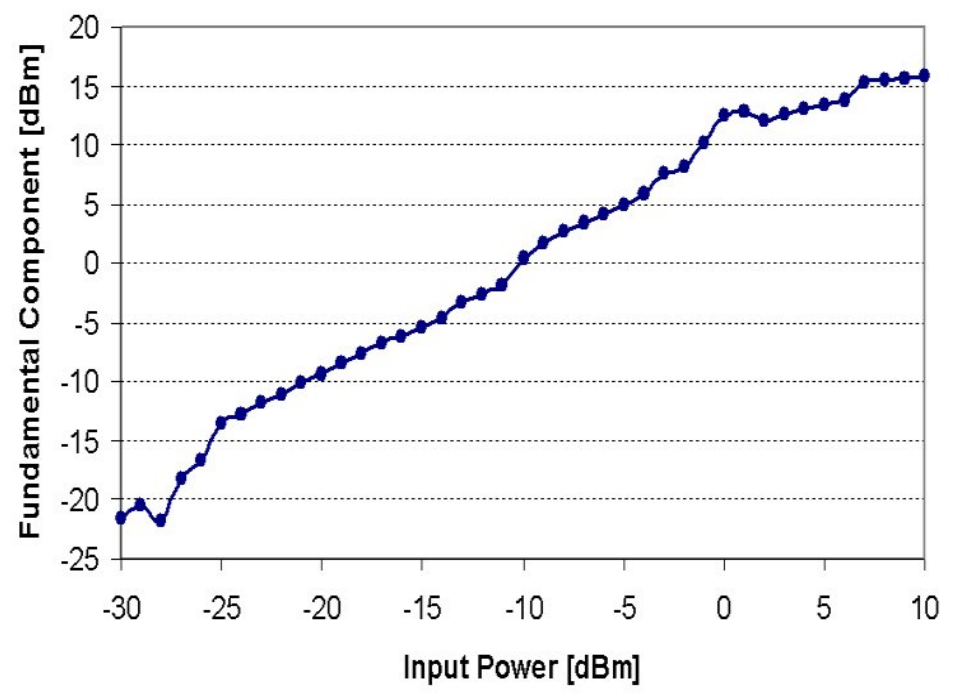

Figure 10. Class E PA fundamental component behavior against input power

Figure 11 shows a comparison between the power efficiency obtained by simulation and the measured one. In this case, the efficiency got by simulation shows a bigger percentage than the one gotten in the characterization process. In the measurement, the efficiency reaches $70 \%$ of power efficiency, meanwhile $83 \%$ is obtained in the simulation. The discrepancy in the efficiency obtained by simulation and the one obtained by measurement is the result of certain circumstances, for example, the attenuation caused by the connectors and cables used to make the measurements, the mismatches between source-circuit and circuit-load. Moreover, in the simulation process, ideal elements were used, but it is well known that transistors and lumped elements have parasitic characteristics. In the 
simulation process, the internal resistor of the transistor was assumed to be close to zero, but the real one is big enough to cause degradation and power consumption, so the efficiency is affected considerably.

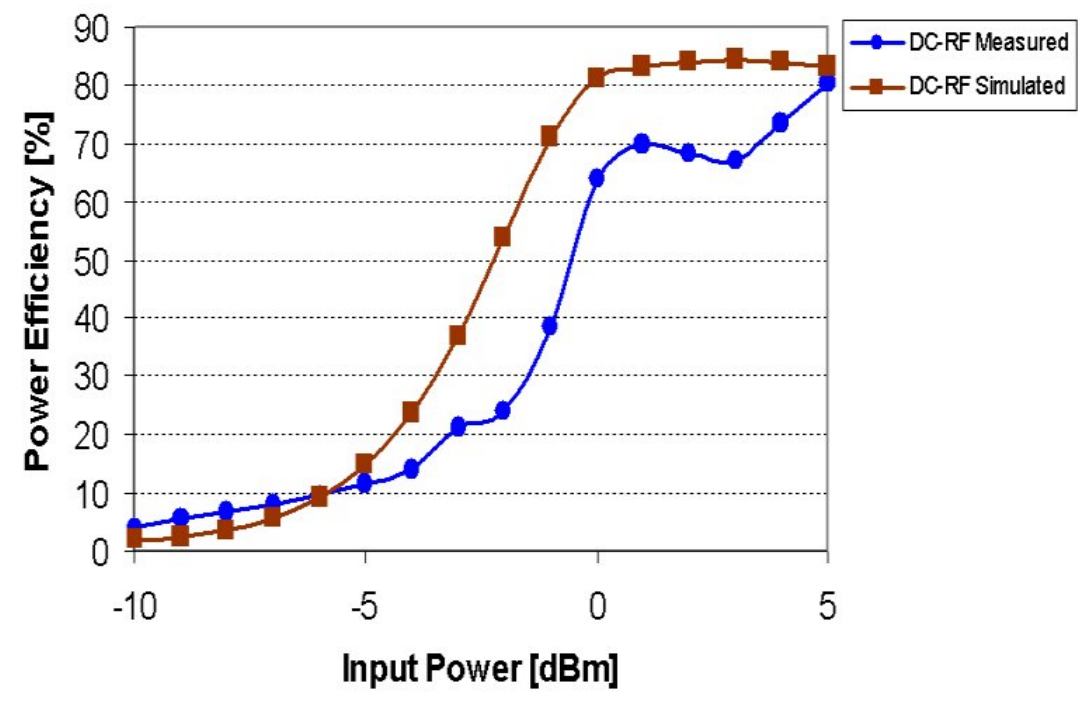

Figure 11. Comparison of simulated and measured power efficiency

As far as power gain is concerned, figure 12 shows the result obtained for this parameter. The gain measured by using a network analyzer shows a magnitude of, almost, $13.2 \mathrm{~dB}$. Meanwhile input and output impedances are shown in figure $13 \mathrm{a}$ and $13 \mathrm{~b}$, respectively. And the VSWR is shown in figure 14 for both cases.

Although a modification of the SMA connectors was made and $50 \Omega$ transmission lines were designed to match the circuit an its ports, a VSWR more than one was obtained due to several reasons. The match between microstrips and connectors is not ideal, the welding procedure can modify the properties of the duroid 6006, changing the impedance of the transmission lines. But the match is good enough to achieve good efficiency and power gain as could be observed in the previous results.

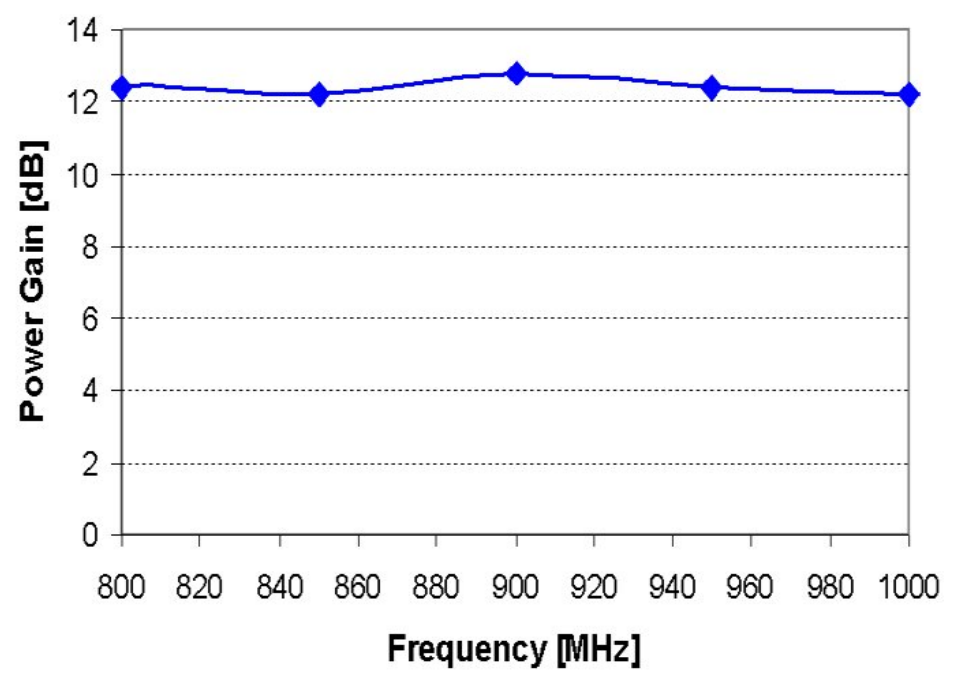

Figure 12. Class E PA power gain 


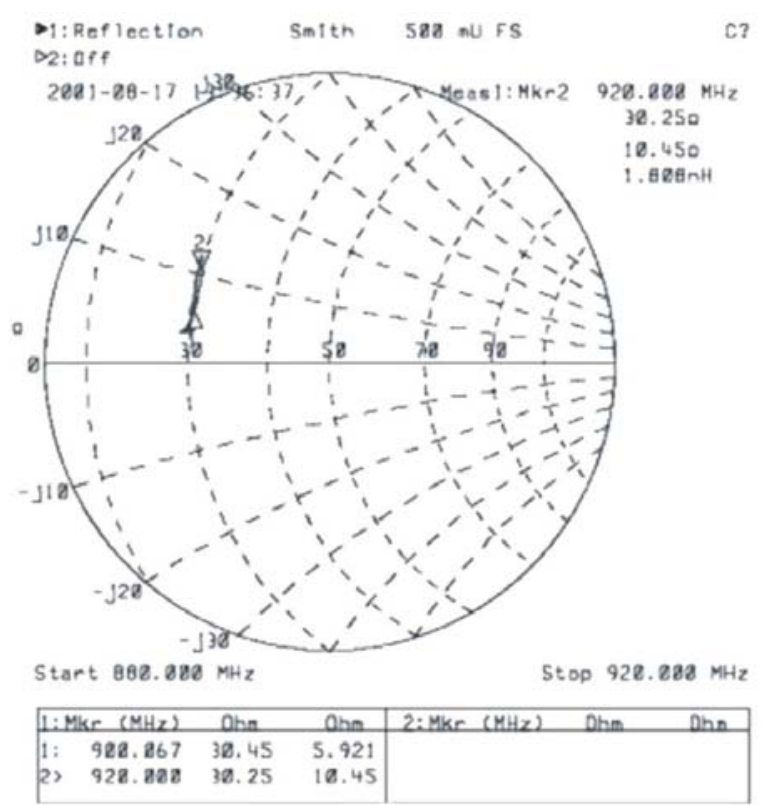

(a)

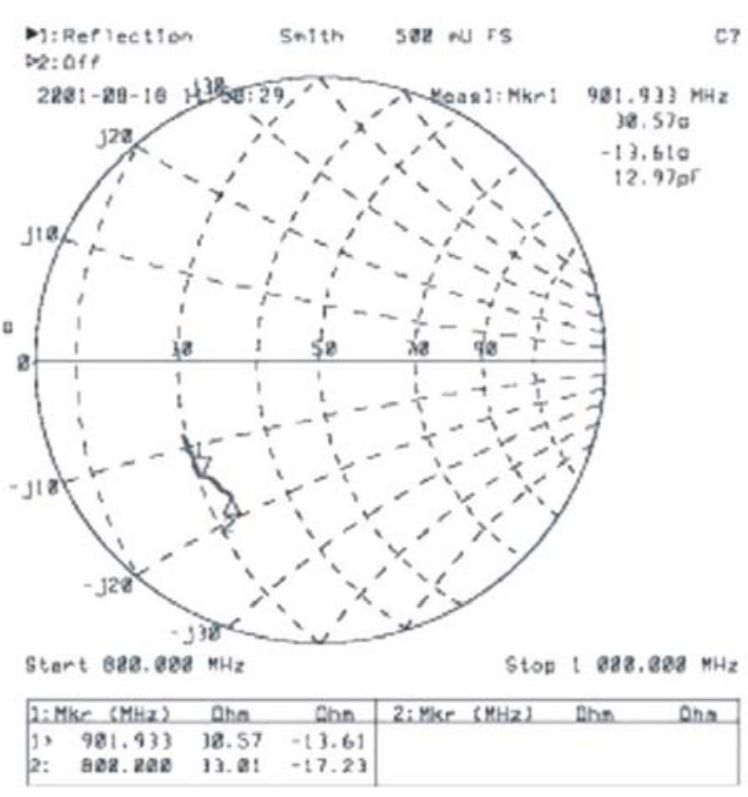

(b)

Figure 13. Characteristic Impedance. a) Input impedance, b) Output impedance

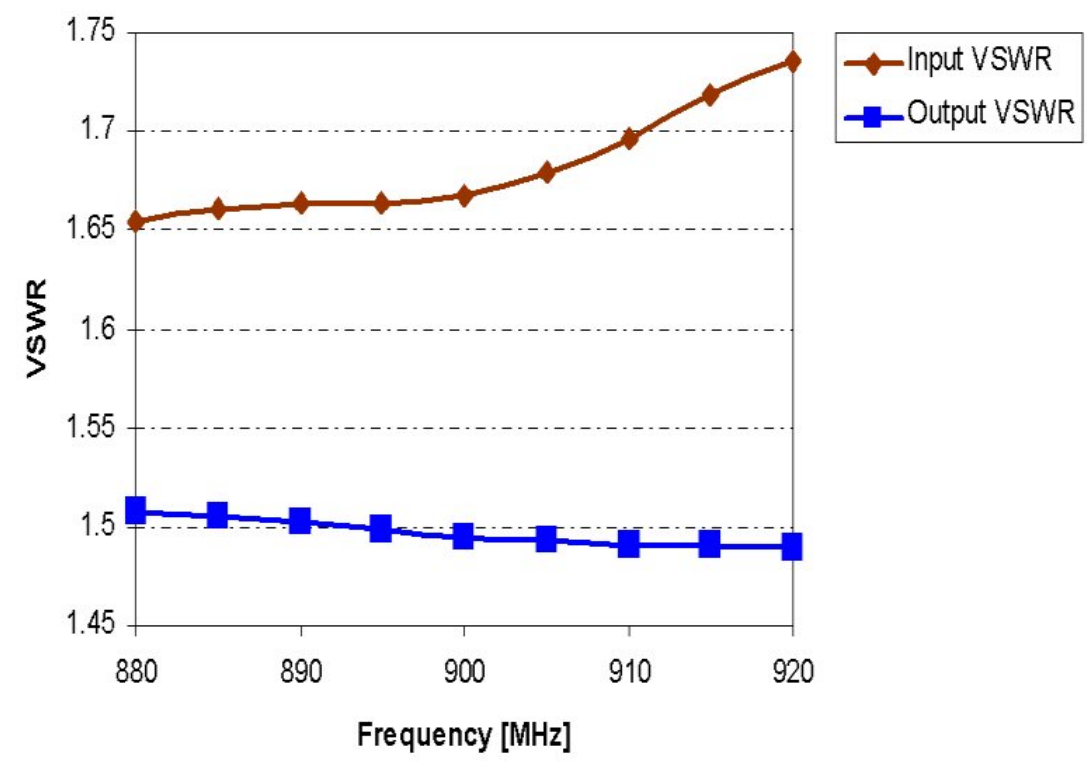

Figure 14. Class E PA voltage standing wave ratio

\section{CONCLUSIONS}

Simulated and experimental characteristics of the SiGe class E power amplifier have close convergence when the bias polarization is set to $2.4 \mathrm{~V}$. These results permit us to assure that the methodology used for its development and SiGe bipolar transistor are appropriated to achieve high efficiency class E PA as it could be seen in figures 12 and 13. 
In simulation process, the obtained efficiency is more than $80 \%$, but when the circuit was characterized, the resulting efficiency is 70\%, which is still a very good result. The difference between these two results is caused by different conditions. Initially, ideal elements were used in the simulation process, which means that no parasitic characteristics in lumped elements were used. However, it is well known that inductors, capacitors and resistors have intrinsic characteristics like parasitic inductances and capacitances which can alter the behavior of the lumped elements at high frequencies, which leads to a loss of energy through the tuned circuit and therefore to a reduction in the efficiency.

The HBT used in the circuit has a resistance with value different from zero, which means a waste of energy as heat. Moreover, in spite of the good features of the transistor, like small junction capacitances, the transition times between on-off and off-on states are not short enough to avoid waste of energy. Which means the transistor does not work as an ideal switch.

Improving transistor technology can achieve better efficiency in class $E$ PA, minimizing the transition periods between on and off states, to avoid loss of energy.

Moreover, a similar efficiency reported in [9] for a class E PA operating at $900 \mathrm{MHz}$ was obtained, but the first disadvantage is that in [9] two power supplies are used, one of them is $3.6 \mathrm{~V}$ and the other is $-4.4 \mathrm{~V}$.

\section{REFERENCES}

[1] Microwave Office ${ }^{\circledR}$, web page: http://uww.mwoffice.com

[2] Cripps, S.C.; RF Power Amplifiers for Wireless Communications; ARTECH HOUSE, 1999

[3] Krauss, H.L.; Bostian, C. W., Raab, F.H.; High Efficiency Power Amplifiers in Solid State Radio Engineering;. USA, John Wiley \& Sons. 1980, pp. 432-476.

[4] Choi, D. \& Long, S. "A Physically Based Analytic Model of FET Class-E Power Amplifiers-Designing for Maximum $P A E^{\prime}$; IEEE Transactions on Microwave Theory and Techniques, Vol. 47, No. 9, September, 1999; pp.1712-1720.

[5] Tirado Méndez, J.A.; Comparación de Diferentes Eestructuras de Amplificadores de Potencia para Sistemas Personales de Comunicación; Tesis de Maestría, CINVESTAV-IPN, México, 2001.

[6] Sokal, N. O.; "Class E-A new Class of High-Efficiency Tuned Single-Ended Switching Power Amplifiers"; IEEE Journal of Solid State Circuits; Vol. SC-10, No.3, June, 1975, pp. 168-176.

[7] Raab, F.H.; "Idealized Operation of the Class E Tuned Power Amplifier"; IEEE Transactions on Circuits and Systems, Vol. CAS-24. No.12, December, 1977, pp. 725-735.

[8] Advanced Design System by Agilent Technologies: http://www.agilent.com

[9] Willkinson, A. J. \& Everard, J. "Transmission line load-network topology for class-E power amplifiers"; IEEE Transactions on microwave theory and techniques, Vol. 49, No. 6, June, 2001, pp 1202-1210.

[10] Rogers Corporation; web page: http://uww.rogers-corp.com

Authors Biography

\section{Hildeberto Jardón Aguilar}

Was born in Tenancingo, Hidalgo, México in 1949. He received the B.Sc. degree in Electrical Engineering from ESIMEIPN, and the Ph.D. degree in Radiosystems form the Moscow Technical University of Telecommunications and Informatics. He is currently working as Full Professor at the Center of Research and Advanced Studies since 1985. His research interests include analysis of nonlinearities in RF and microwave circuits, Electromagnetic Compatibility and Photonic Systems. He is author of 5 books and more than 100 technical papers in journals and symposiums. He is member of the Popov Society and he has level II in the SNI of Mexico. 


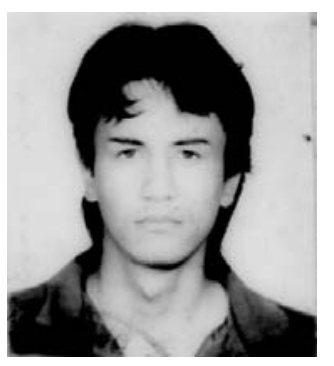

José Alfredo Tirado Méndez

Was born in Mexico City, México in 1976. He received the B.Sc. degree in Electronics and Digital Systems from UAMAzcapotzalco, the M.Sc. degree in Telecommunications from CINVESTAV. He joined the Microwave and Remote Sensing Laboratory at the University of Massachusetts in 2001. He is currently working as Research Assistant and making his Ph.D. in Telecommunications in CINVESTAV-Mexico. His research interests are electromagnetic compatibility and nonlinearities as well as RF and microwave circuits design for personal communication systems. 